\title{
Esophago-pericardial Fistula Induced Community Acquired Methicillin Resistant Staphylococcus Aureus (CA-MRSA) Cardiac Tamponade - A Rare Case Report and Literature Review
}

\author{
Pramod Theetha Kariyanna1, Apoorva Jayarangaiah ${ }^{2}$, Ronald Pedalino ${ }^{1,3}$, Sudhanva Hegde ${ }^{1,3}$, \\ Jonathan D. Marmur', Aarti Shenoy ${ }^{1}$, Michael Ashamalla ${ }^{4}$, Justina Ray ${ }^{1}$, Samy I. McFarlane, ${ }^{1, *}$ \\ ${ }^{1}$ Divisions of Cardiovascular Disease, Endocrinology and Nephrology, Department of Internal Medicine, State University of New York, \\ Downstate Medical Center, Brooklyn, New York, U.S.A- 11203 \\ ${ }^{2}$ Department of Internal Medicine, Wake Forest University, Baptist Health System, Winston-Salem, North Carolina, U.S.A-27157 \\ ${ }^{3}$ Division of Cardiology, New York City Health and Hospitals- Kings County Medical center, Brooklyn, New York, U.S.A- 11203 \\ ${ }^{4}$ Hofstra Northwell school of Medicine, Division of Medicine, Hempstead, New York, U.S.A- 11449 \\ *Corresponding author: Samy.mcfarlane@downstate.edu
}

\begin{abstract}
Community acquired methicillin resistant Staphylococcus aureus (CA-MRSA) infection is a matter of public health concern. The incidence of community acquired Staphylococcus aureus (CA-MRSA) is rising. To date only 12 cases of CA-MRSA pericarditis and seven cases of esophageal cancer related purulent pericarditis have been reported. We here present a 54 year old woman who presented with cardiac tamponade that was noted to be purulent and in whom esophagopericardial fistula secondary to squamous cell esophageal cancer was discovered subsequently. Purulent pericardial fluid subsequently grew MRSA. Patient succumbed despite appropriate management with antibiotics.
\end{abstract}

Keywords: esophago-pericardial fistula, MRSA, cardiac tamponade, esophageal cance

Cite This Article: Pramod Theetha Kariyanna, Apoorva Jayarangaiah, Ronald Pedalino, Sudhanva Hegde, Jonathan D. Marmur, Aarti Shenoy, Michael Ashamalla, Justina Ray, and Samy I. McFarlane, "Esophago-pericardial Fistula Induced Community Acquired Methicillin Resistant Staphylococcus Aureus (CA-MRSA) Cardiac Tamponade - A Rare Case Report and Literature Review.” American Journal of Medical Case Reports, vol. 6, no. 6 (2018): 109-113. doi: 10.12691/ajmcr-6-6-3.

\section{Introduction}

The infection rates of hospital acquired methicillin resistant Staphylococcus aureus (MRSA) have been stable recently; in contrast, the incidence of community acquired methicillin resistant Staphylococcus aureus (CA-MRSA) is increasing in alarming rates [1]. CA-MRSA is a very rare cause of pericarditis and to date only 12 cases have been reported. We present a case of a suppurative cardiac tamponade caused by CA-MRSA pericarditis in a 54 year old African- American female. She was subsequently found to have squamous cell carcinoma of the esophagus that led to a fistula into the pericardium resulting in the development of CA-MRSA cardiac tamponade.

\section{Case Report}

A 54 year old postmenopausal female with past medical history of 35 pack years history of smoking and alcohol abuse presented with worsening dyspnea for four months, decrease in exercise tolerance to one block from four blocks four months ago, loss of appetite and 41 pound weight loss and worsening bilateral lower limb swelling for four months. She had five episodes of bright red blood per rectum in last five weeks. She was afebrile at presentation, heart rate was 98 beats per minute, blood pressure was 121/50 mm $\mathrm{Hg}$, and respiratory rate was 18 cycles per minute. Physical examination revealed jugular venous distension, distant heart sounds, rales were heard in all lung fields and bilateral lower limb edema till mid thighs. Investigations including complete blood count, comprehensive metabolic panel, venous blood gas. Investigations revealed anemia with hemoglobin at $10.7 \mathrm{~g} / \mathrm{dL}$, elevated white blood cell count at $9.7 \times 10{ }^{9} / \mathrm{L}$ with $82 \%$ neutrophils, hyponatremia (123 $\mathrm{mEq} / \mathrm{L})$, hyperkalemia $(6.6 \mathrm{mEq} / \mathrm{L})$, elevated blood urea nitrogen $128 \mathrm{mg} / \mathrm{dL}$, serum creatinine $4.08 \mathrm{mg} / \mathrm{dL}$, elevated liver enzymes (aspartate aminotransferase $118 \mathrm{u} / \mathrm{L}$, alanine aminotransferase $122 \mathrm{u} /$ Land alkaline phosphatase $237 \mathrm{u} / \mathrm{L}$. A venous blood gas analysis revealed a $\mathrm{pH}$ of 7.219, pCO2 of $28.5 \mathrm{~mm} \mathrm{Hg}$, pO2 $28.4 \mathrm{~mm} \mathrm{Hg}$, oxygen saturation of $32.6 \%$, bicarbonate level of $8 \mathrm{mmol} / \mathrm{L}$ suggesting metabolic alkalosis. Electrocardiogram revealed sinus tachycardia and low voltage QRS complexes (Figure 1). 


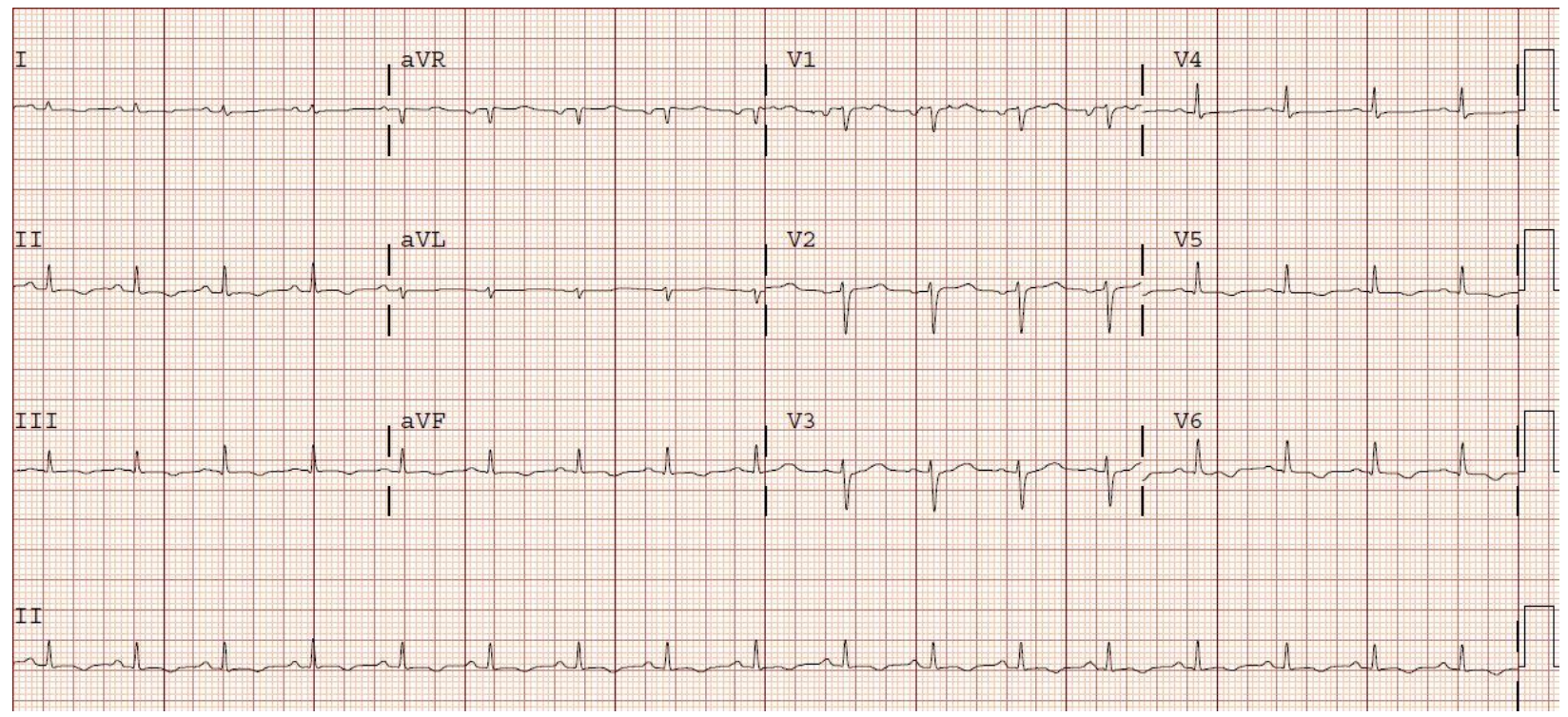

Figure 1. Electrocardiogram of the patient which revealed sinus tachycardia and low voltage QRS complexes

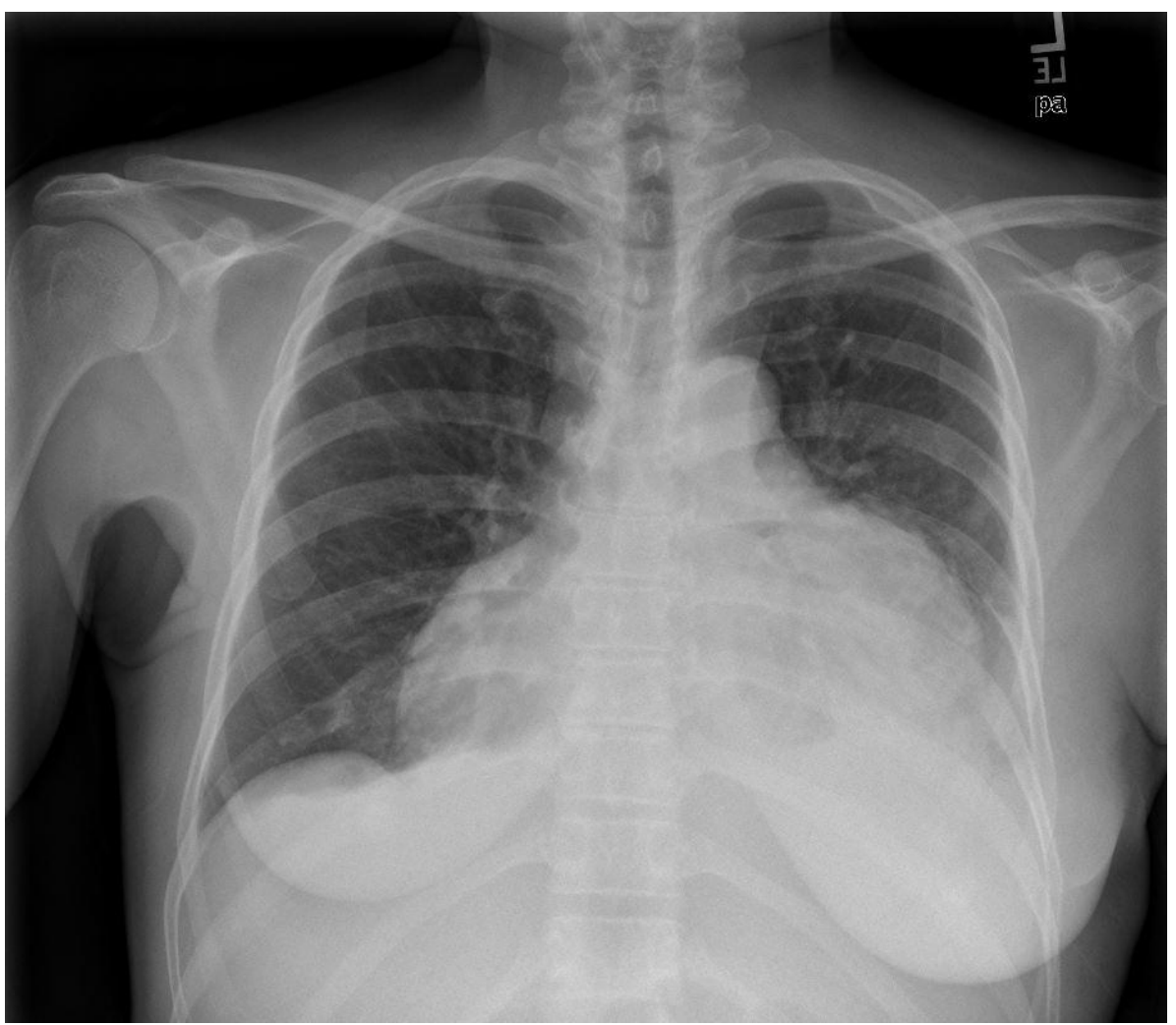

Figure 2. Chest X-ray showing increase in the cardiac silhouette

A chest X-ray obtained revealed enlarged cardiac silhouette (Figure 2). A bedside 2D transthoracic echocardiogram revealed large pericardial effusion with tamponade physiology. An emergent pericardial window was placed for pericardial fluid drainage by cardiothoracic surgery consultants in the operating room. The pericardial fluid was noted to be purulent hence ceftriaxone and vancomycin were started after obtaining two sets of blood cultures. Investigations have been listed in Table 1. Blood culture and serous pleural fluid cultures did not yield any growth, however pericardial fluid culture grew methicillin resistant Staphylococcus aureus (MRSA), hence vancomycin was continued. She had two more episodes of melena which raised the concern for gastrointestinal malignancy. Patient refused endoscopy and colonoscopy hence esophagogram and abdominal computed tomography (CT) was performed. Hence a esophagogram (Figure 3, Figure 4) was performed which revealed long irregular stricture involving thoracic esophagus with fistula to the pericardium. Endoscopic biopsy of the mass was consistent with squamous cell carcinoma (SCC) of the esophagus. A full body positive emission tomography (PET) scan revealed large hypermetabolic esophageal mass with multiple hypermetabolic foci noted inferior to the cervical spine, lower cervical lymph nodes, right pleura, left chest wall and multiple retropharyngeal lymph nodes (Figure 5). Multiple peritoneal adenopathy noted on CT abdomen were localized but obscure on PET scan. An esophageal stent was placed closed the 
esophago-pericardial fistula to maintain patency of the esophageal lumen (Figure 6). Patient signed do not resuscitate orders. Her hospital course was complicated by septic shock and she passed away from cardiac arrest.

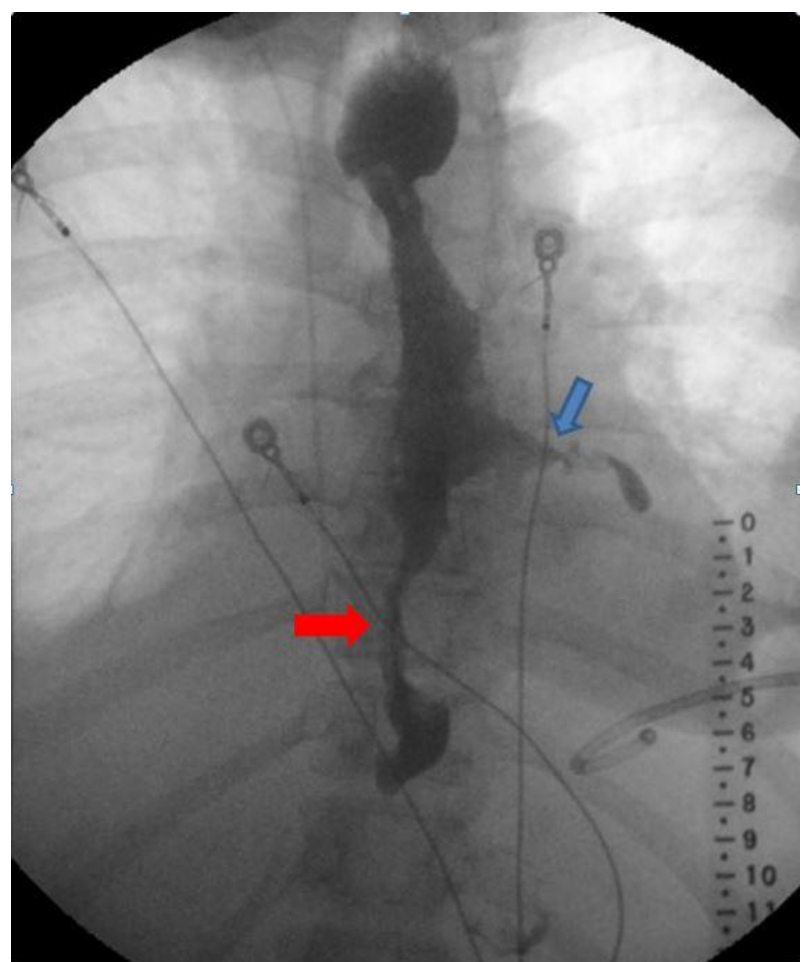

Figure 3. Esophagogram showing luminal narrowing of the esophagus (red arrow) and pericardioesophageal fistula (blue arrow)

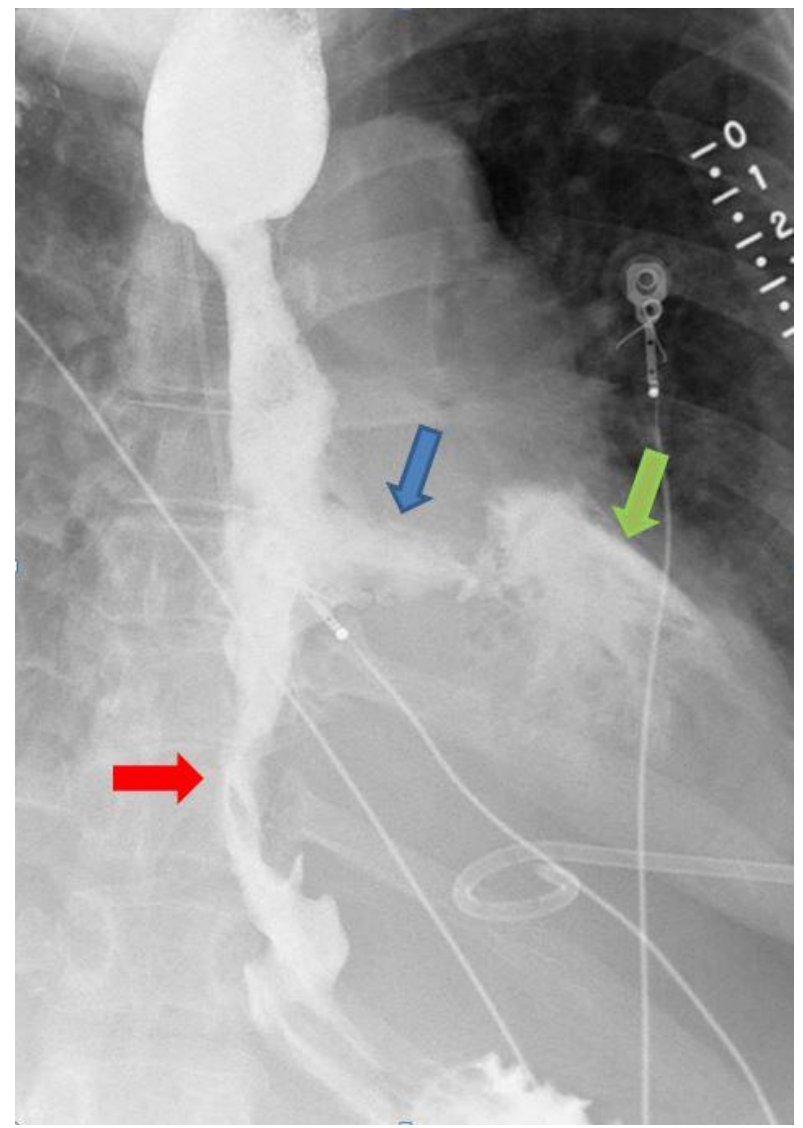

Figure 4. Esophagogram showing luminal narrowing of the esophagus (red arrow), pericardioesophageal fistula (blue arrow) and dye in the pericardium (green arrow)

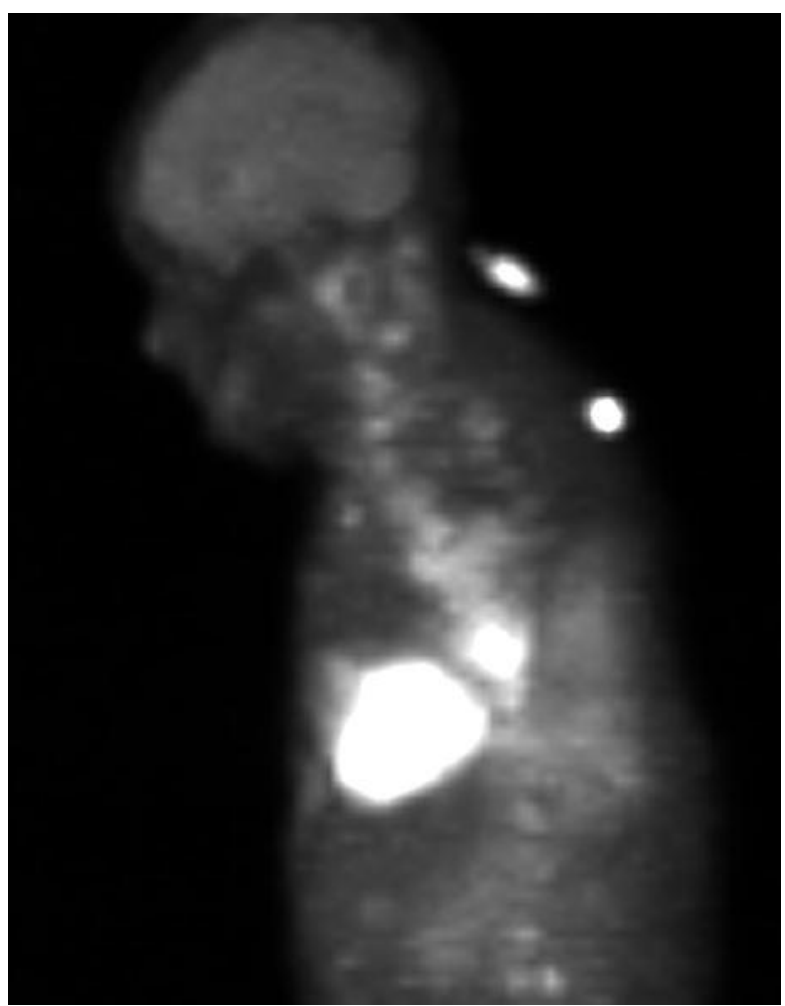

Figure 5. Positive emission tomography (PET) scan revealed large hypermetabolic esophageal mass

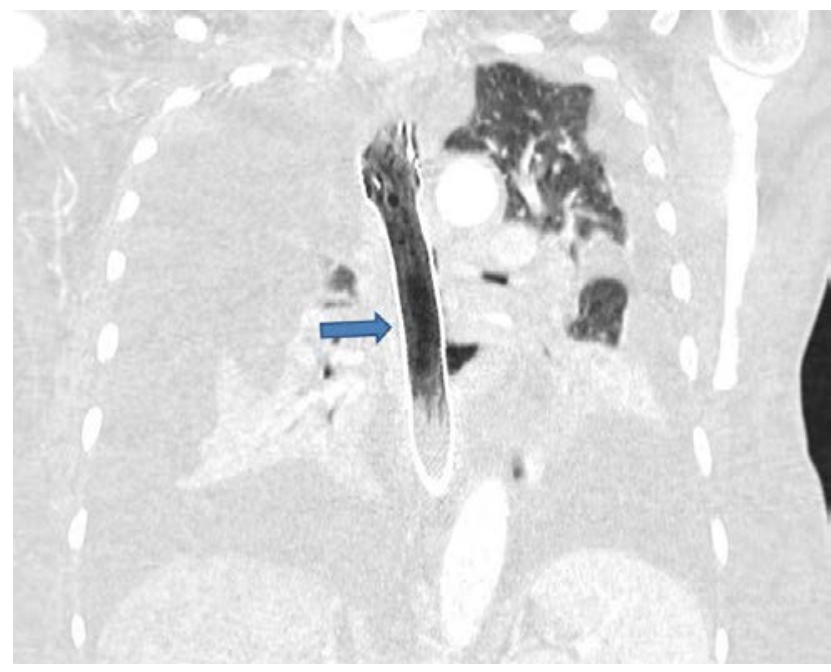

Figure 6. Computed tomography revealing right and left pleural effusion and esophageal stent (blue arrow)

\section{Discussion}

Although the infection rates of hospital acquired methicillin resistant Staphylococcus aureus (HA- MRSA) has been stable recently, the incidence of community acquired Staphylococcus aureus (CA-MRSA) is increasing at alarming rates [1]. Cardiac tamponade is life threatening, slow or rapid compression of the heart due to the pericardial accumulation of fluid, pus, blood, clots or gas, as a result of effusion, trauma or rupture of the heart [2]. Purulent pericarditis is defined as an infection in the pericardial space that produces macroscopically or microscopically purulent material [3]. Primary purulent pericarditis is extremely rare, The mechanisms that lead to secondary 
purulent pericarditis are extension of infection from: intrathoracic site, intracardiac site, hematogenous spread, subdiaphragmatic site or trauma/surgery [4]. The incidence of purulent pericarditis in pre-antibiotic era was 1 in 254; in antibiotic era the incidence fell to 1 in 18,000 individuals $[5,6]$. Klacsmann et al review of 200 cases of purulent pericarditis revealed Streptococcus pneumoniae as the most common cause in pre-antibiotic era (1889-1943), with pneumonia being the most common primary source of infection; Staphylococcus aureus dominates the picture in post antibiotic era. Most of these cases of S.aureus purulent pericarditis were associated with thoracic surgery, chronic renal failure, diabetes, carcinomas [7]. Purulent pericarditis is always fatal if left untreated and even with appropriate treatment the mortality rate is $40 \%$ [8].

In recent years, hospital acquired MRSA (HA-MRSA) rates have been relatively stable while CA-MRSA infection rates are on the surge in various settings and patient population such as outpatient clinics, emergency department, children, native americans, aboriginal population, men who have sex with men and athletes [1]. It is debatable if CA-MRSA replaces or adds to the disease burden of its hospital counterpart [9]. To date only 12 cases of CA-MRSA purulent pericarditis have been reported. Most of these cases of CA-MRSA pericarditis were managed with pericardial drainage and antibiotics (Table 1) [9-19]. Esophageal cancer is a rare cause of purulent pericarditis and eight cases have been reported in the literature; MRSA was only reported by Gilles et al. (Table 2) [20-26].

Early diagnosis and management of CA-MRSA pericarditis/cardiac tamponade with pericardiocentesis and appropriate antibiotics can be life saving. This is of prime importance as MRSA pericarditis has a high mortality rate despite appropriate treatment [8]. The patient presented here had CA-MRSA cardiac tamponade secondary to per esophagopericardial fistula from SCC of esophagus. The patient never experienced fever despite having severe CA-MRSA infection, yet another atypical feature in presentation of a purulent infection. Milder and slower onset of cardiovascular symptoms and signs in this case can be explained by the ability of pericardium to accommodate huge amounts of fluid in slow onset chronic pericarditis and neurohumoral adjustment responses; cardiac tamponade sets in once the "last drop" phenomenon sets in [2].

Table 1. Cases of CA-MRSA purulent pericarditis reported in literature

\begin{tabular}{|l|l|l|}
\hline Serial number & Cases of CA-MRSA purulent pericarditis reported in literature and the year of publication & Number of cases reported \\
\hline 1. & LT Sugat patel et al, 2006 [9] & 1 \\
\hline 2. & Yian-Ping Lee et al, 2008 [10] & 1 \\
\hline 3. & Anupama Shivaraju et al, 2008 [11] & 1 \\
\hline 4. & R. Rozenbaum et al, 2009 [12] & 1 \\
\hline 5. & M Ammar Hussam et al, 2010 [13] & 1 \\
\hline 6. & Natasha Purai Arora et al, 2012 [14] & 1 \\
\hline 7. & Jeffery.E.Lutmer et al, 2012 [15] & 2 \\
\hline 8. & Yu Kurahara et al, 2013 [16] & 1 \\
\hline 9. & Vasudevan Anil Kumar et al, 2013 [17] & 1 \\
\hline 10. & Kavitha Bagavathy et al, 2014 [18] & 1 \\
\hline 11. & Tracy A.Drake et al, 2015 [19] & 1 \\
\hline
\end{tabular}

Table 2. Cases of esophageal cancer that were associated with purulent pericarditis

\begin{tabular}{|c|c|c|c|c|}
\hline $\begin{array}{l}\text { Serial } \\
\text { number }\end{array}$ & $\begin{array}{l}\text { Cases of esophageal cancer that } \\
\text { were associated with purulent } \\
\text { pericarditis }\end{array}$ & $\begin{array}{l}\text { Cardiac tamponade/ pericarditis was } \\
\text { the presentation of esophageal cancer }\end{array}$ & Organism isolated & number of cases \\
\hline 1 & Ben Saussan T et al, 1992 [20] & Yes & $\begin{array}{l}\text { Mixed infection: } \\
\text { Streptococcus milleri, } \\
\text { Peptostreptococcus micos, } \\
\text { Eubacterium, Bacteriodes } \\
\text { ureoliticus, Bacterioides } \\
\text { melaninogenicus }\end{array}$ & 1 \\
\hline 2 & Muto et al, 1999 [21] & Yes & Streptococcus milleri & 2 \\
\hline 3 & Kohl O et al, 1999 [22] & Yes & Coagulase negative Staphylococcus & 1 \\
\hline 4 & Kaufman et al, 2003 [23] & No & $\begin{array}{l}\text { Streptococcus milleri } \\
\text { alpha hemolytic streptococcus }\end{array}$ & 1 \\
\hline 5 & Gilles et al , 2003 [24] & Yes & MRSA & 1 \\
\hline 6 & Nessler et al, 2006 [25] & Yes & Streptococcus constellatus & 1 \\
\hline 7 & Takayama et al , 2013 [26] & No & $\begin{array}{l}\text { Mixed infection: Streptococcus } \\
\text { sanguis, Staphylococcus } \\
\text { epidermidis and Streptococcus } \\
\text { constellatus. }\end{array}$ & 1 \\
\hline
\end{tabular}




\section{Conclusion}

To our knowledge, the case we present is the thirteenth reported case of CA-MRSA pericarditis and ninth ever reported case of purulent pericarditis due to esophageal cancer induced esophgopericardial fistula. The mortality rate of purulent pericarditis is high despite treatment [8]. Early diagnosis of CA-MRSA purulent cardiac tamponade/pericarditis could be life saving.

\section{Acknowledgements}

This work is supported, in part, by the efforts of Dr. Moro O. Salifu M.D., M.P.H., M.B.A., M.A.C.P., Professor and Chairman of Medicine through NIH Grant number S21MD012474.

\section{References}

[1] Popovich KJ, Weinstein RA, Hota B. Are community-associated methicillin-resistant Staphylococcus aureus (MRSA) strains replacing traditional nosocomial MRSA strains?. Clinical Infectious Diseases. 2008 Mar 15; 46(6):787-94.

[2] Spodick DH. Acute cardiac tamponade. American heart journal. 1991 Dec 1; 122(6): 1794.

[3] Rubin RH, Moellering Jr RC. Clinical, microbiologic and therapeutic aspects of purulent pericarditis. The American journal of medicine. 1975 Jul 1; 59(1): 68-78.

[4] Klacsmann PG, Bulkley BH, Hutchins GM. The changed spectrum of purulent pericarditis: an 86 year autopsy experience in 200 patients. The American journal of medicine. 1977 Nov 1; 63(5): 666-73.

[5] Sagristà-Sauleda J, Barrabés JA, Permanyer-Miralda G, SolerSoler J. Purulent pericarditis: review of a 20-year experience in a general hospital. Journal of the American College of Cardiology. 1993 Nov 15; 22(6): 1661-5.

[6] Parikh SV, Memon N, Echols M, Shah J, McGuire DK, Keeley EC. Purulent pericarditis: report of 2 cases and review of the literature. Medicine. 2009 Jan 1; 88(1): 52-65.

[7] Mizuguchi Y, Takeda S, Miyashita M, Ikezaki H, Nakajima Y, Akada S, Makino H, Futami R, Arai M, Sasajima K, Tajiri T. A case of cardiac tamponade following esophageal resection. Journal of anesthesia. 2005 Aug 1; 19(3): 249-51.

[8] Furak J, Olah T, Szendrenyi V, Horvath OP, Balogh A. Esophagopericardial fistula caused by recurrent esophageal tumor. Magyar sebeszet. 1999 Apr; 52(2): 89-91.

[9] Patel S, Maves R, Barrozo CP, Mullens F, Russell K, Truett A Deroo T. Mycotic pseudoaneurysm and purulent pericarditis attributable to methicillin-resistant Staphylococcus aureus. Military medicine. 2006 Aug 1; 171(8): 784-7.

[10] Lee YP, Hoi WH, Wong RC. A case of myopericarditis in a patient with methicillin-resistant Staphylococcus aureus community-acquired pneumonia. Annals of the Academy of Medicine, Singapore. 2008 Mar; 37(3): 243.

[11] Shivaraju A, Luu J, Bratis C, Akhter N, Stamos T. Communityacquired MRSA pericarditis. Cardiology Review. 2008 Jan 1; 25(1): 39-43.
[12] Rozenbaum R, Sampaio MG, Batista GS, Garibaldi AM, Terra GM, Souza MJ, Vieira EN, Silva-Carvalho MC, Teixeira LA, Figueiredo AM. The first report in Brazil of severe infection caused by community-acquired methicillin-resistant Staphylococcus aureus (CA-MRSA). Brazilian journal of medical and biological research. 2009 Aug; 42(8): 756-60.

[13] Hussam MA, Ragai MF, Iman MF, Zakaria A. Communityacquired methicillin-resistant Staphylococcus aureus pericarditis presenting as cardiac tamponade. Southern medical journal. 2010 Aug; 103(8): 834-6.

[14] Arora NP, Kottam A, Mahajan N, Bhasin B, Krishnamoorthi R, Shenoy M, Afonso LC. Purulent pericardial effusion from community-acquired methicillin-resistant Staphylococcus aureus. The American journal of the medical sciences. 2012 Aug 1; 344(2): 160-2.

[15] Lutmer JE, Yates AR, Bannerman TL, Marcon MJ, Karsies TJ. Purulent pericarditis secondary to community-acquired, methicillin-resistant Staphylococcus aureus in previously healthy children. A sign of the times?. Annals of the American Thoracic Society. 2013 Jun; 10(3): 235-8.

[16] Kurahara Y, Kawaguchi T. Cardiac Tamponade with Communityacquired Methicillin-resistant Staphylococcus aureus Pericarditis. Internal Medicine. 2013; 52(15): 1753.

[17] Kumar VA, Nair N, Thachathodiyl R, Nandakumar A, Dinesh KR, Thatcher E, Karim S, Biswas R. Molecular characterization of methicillin-resistant staphylococcus aureus causing fatal purulent pericarditis. Journal of laboratory physicians. 2013 Jul; 5(2): 136.

[18] Bagavathy K, Raju SK, Joseph R, Kumar A. Cardiac tamponade complicating purulent pericarditis due to community acquired methicilin resistant Staphylococcus aureus (CA-MRSA). Connecticut medicine. 2014 Mar; 78(3): 163-5.

[19] Drake T, Goldstein D. Heart of Gold: A Case of CommunityAcquired Mrsa Pericarditis with Tamponade [abstract].Journal of Hospital Medicine. 2015; 10 (suppl 2). https://www.shmabstracts.com/abstract/heart-of-gold-a-case-ofcommunity-acquired-mrsa-pericarditis-with-tamponade/. Accessed May 18, 2018.

[20] Ben TS, Nousbaum JB, Garo B, Pouchelle C, Boles JM, Robaszkiewicz M, Gouerou H, Garre M. Purulent pericarditis revealing esophageal cancer. InAnnales de medecine interne 1992 (Vol. 143, No. 4, pp. 279-280).

[21] Muto M, Ohtsu A, Boku N, Tajiri H, Yoshida S. Streptococcus milleri infection and pericardial abscess associated with esophageal carcinoma: report of two cases. Hepato-gastroenterology. 1999; 46(27): 1782-4.

[22] Kohl O, Schäffer R, Doppl W. Purulent pericarditis as an initial manifestation of esophageal carcinoma. Deutsche medizinische Wochenschrift (1946). 1999 Apr; 124(13): 381-5.

[23] Kaufman J, Thongsuwan N, Stern E, Karmy-Jones R. Esophagealpericardial fistula with purulent pericarditis secondary to esophageal carcinoma presenting with tamponade. The Annals of thoracic surgery. 2003 Jan 1; 75(1): 288-9.

[24] Touati GD, Carmi D, Nzomvuama A, Marticho P. Purulent pericarditis caused by malignant oesophago-pericardial fistula. European journal of cardio-thoracic surgery. 2003 Nov 1; 24(5): 847-9.

[25] Nessler B, Paradowski A, Nessler J, Libionka A, Misztal M, Latacz P, Piwowarska W, Nalepa P, Włodarczyk J, Olechnowicz $\mathrm{H}$. Case report Cardiac tamponade as the first symptom of oesophageal carcinoma-a case report. Kardiologia Polska (Polish Heart Journal). 2006; 64(3): 312-5.

[26] Takayama T, Okura Y, Funakoshi K, Sato T, Ohi H, Kato T. Esophageal cancer with an esophagopericardial fistula and purulent pericarditis. Internal Medicine. 2013; 52(2): 243-7. 